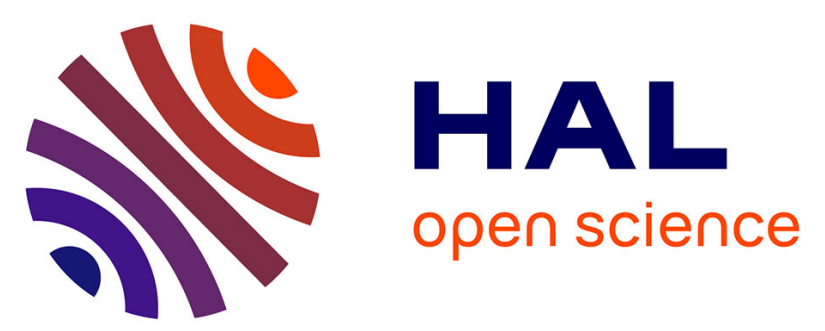

\title{
THERMOMETRY AT VERY LOW TEMPERATURES WITH POLARIZED NEUTRONS, APPLICATION TO THE SEARCH FOR THE 3He MAGNETIC STRUCTURE
}

\author{
Angélique Benoit, J. Floquet, D. Rufin, J. Schweizer
}

\section{To cite this version:}

Angélique Benoit, J. Floquet, D. Rufin, J. Schweizer. THERMOMETRY AT VERY LOW TEMPERATURES WITH POLARIZED NEUTRONS, APPLICATION TO THE SEARCH FOR THE 3He MAGNETIC STRUCTURE. Journal de Physique Colloques, 1982, 43 (C7), pp.C7-311-C7-316. 10.1051/jphyscol:1982746 . jpa-00222353

HAL Id: jpa-00222353 https://hal.science/jpa-00222353

Submitted on 1 Jan 1982

HAL is a multi-disciplinary open access archive for the deposit and dissemination of scientific research documents, whether they are published or not. The documents may come from teaching and research institutions in France or abroad, or from public or private research centers.
L'archive ouverte pluridisciplinaire HAL, est destinée au dépôt et à la diffusion de documents scientifiques de niveau recherche, publiés ou non, émanant des établissements d'enseignement et de recherche français ou étrangers, des laboratoires publics ou privés. 
THERMOMETRY AT VERY LOW TEMPERATURES WITH POLARIZED NEUTRONS, APPLICATION TO THE SEARCH FOR THE ${ }^{3}$ He MAGNETIC STRUCTURE

\author{
A. Benoit ${ }^{*}$, J. Flouquet ${ }^{*}$, D. Rufin ${ }^{*++}$ and J. Schweizer ${ }^{+}$ \\ * CRTBT-CNRS, B.P. 166X, 38042 Grenoble Cedex, France \\ ${ }^{++}$Air-Liquide, 38360 Sassenage, France \\ ${ }^{+} D N / R F G-C E N G$, B.P. 85X, 38041 Grenoble Cedex, France
}

Résumé. - Les thermomètres, en dessous de $20 \mathrm{mK}$, nécessitent généralement un étalonnage. Ce $n$ 'est pas le cas pour les thermomètres qui mesurent la polarisation des spins nucléaires provoquée par un champ magnétique appliqué, en 1 'absence de moments magnétiques électroniques. On peut réaliser de telles mesures avec précision en utilisant des neutrons polarisés, soit par diffraction, soit par absorption. On décrit un montage destiné à étudier l'ordre magnétique dans ${ }^{3}$ He solide en dessous de $1 \mathrm{mK}$. A ces températures le couplage thermique entre les différents éléments $n$ 'est pas toujours bon. Pour connaitre la température d'un élément il faut la mesurer directement et in situ. $C^{\prime}$ est ainsi qu'on mesure la température du porte-échantillon en cuivre par diffraction de neutrons polarisés et celle de 1'3e solide par des mesures de transmission, 1'absorption dépendant du spin des neutrons. On montre ainsi que $1^{13}$ He a été refroidi en dessous de sa température de Néel.

\begin{abstract}
Most of the thermometers, below $20 \mathrm{mK}$, require calibration in their temperature range before use. This is not the case for thermometers based on the measurement of the nuclear spin polarization resulting from an applied magnetic field, in the absence of electronic magnetic moments. Such measurements can be achieved accurately with polarized geutrons, either by coherent scattering or by absorption measurements. An experimental set up, for

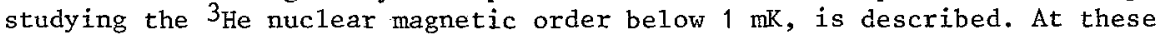
temperatures the thermal coupling between the different parts of the set up is uncertain. To know the temperature of one given element of the set up, it is necessary to measure it in situ and directly; polarized neutrons are very well adapted. Diffraction measurements give the temperature of the copper cell which contains $3 \mathrm{Fe}$, while transmission measurements indicate the temperature of the ${ }^{3} \mathrm{He}$ nuclear spins and show whether they have been cooled below the transition.
\end{abstract}

1. Introduction. - Despite the large variety of experiments now performed below $10 \mathrm{mk}$, the applicability of a thermometer ( $\mathrm{Th}$ ) to an experiment must be considered for each case. The difficulty is to be sure that the thermometer is in equilibrium with the measured sample. In parallel with the usual notion of primary and secondary thermometers we must consider whether the probe is or is not in direct thermal contact with the material (M). In the case of an indirect link between Th and $M$, a simple rule is that pure electronic contacts minimize the thermal resistance between two solids whereas the thermal resistance (Kapitza resistance $\mathrm{R}_{\mathrm{K}}$ ) between two solids or a solid and a liquid via a sole phonon coupling is high (1). For example, a typical value of $R_{K}$ is $10^{-2} T^{-3} K^{4} \mathrm{~m}^{2} \mathrm{~W}^{-1}$. Heating ( $\dot{Q}$ ) one of the constituents (Th or $M$ ) will introduce a temperature difference $\delta \mathrm{T}=\mathrm{T}_{\mathrm{Th}}-\mathrm{T}_{\mathrm{M}}$ given by the relation :

$$
\delta \mathrm{T}=\frac{\mathrm{R}_{\mathrm{K}}}{\mathrm{S}} \dot{\mathrm{Q}} \quad \text { (S being the interface area) }
$$

For $S=0.1 \mathrm{~m}^{2}$, at $10 \mathrm{mK}, \frac{\delta \mathrm{T}}{\mathrm{T}}<1 \%$ corresponds to a measured power $\mathrm{Q}<10^{-9} \mathrm{~W}$.

Below $5 \mathrm{mK}$, current thermometers are the Pt NMR thermometer of pure Pt metal 
and the pressure-temperature dependence on the 3He melting curve. The first one needs the use of powderin order to minimize the parasitic heating produced by the radiofrequency power (1); the second implies to work on the ${ }^{3} \mathrm{He}$ melting curve or to use a supplementary electronic coupling to the experimental chamber. Experimentally, these two thermometers lead to an increase in size of the experimental chamber. Furthermore, for the purpose of demonstrating that it is possible to perform neutron diffraction on solid ${ }^{3} \mathrm{He}$ below its magnetic ordering temperature $\left(\mathrm{T}_{\mathrm{N}}=1 \mathrm{mK}\right.$ on the melting curve), they are in fact meaningless as they are indirect probes. The neutron absorption cross section of ${ }^{3} \mathrm{He}$ nuclei is very large ( $\sigma \sim 3000$ barns for $\lambda=1 \AA$ ) and the heating produced by the absorption of $10^{4}$ neutrons per second is $10^{-9} \mathrm{H}$. To show that a 3 He solid target can be cooled in the presence of a neutron beam, it is therefore necessary to perform the temperature measurements of the irradiated ${ }^{3} \mathrm{He}$ target directly and in situ. We have then used direct probes based on the variation of the nuclear polarization $\left(f_{\mathrm{n}}\right)$ with temperature, for a given applied field $(H)$. The measurement of nuclear polarization can be easily achieved with polarized neutrons, either by coherent scattering (Bragg reflection) or by spin dependent absorption.

We discuss in the following the sensitivity of nuclear polarization as a thermometer, the scattering and the selective absorption of polaxized neutrons by a spin polarized target. Finally we describe the experimental set up of the ${ }^{3}$ He experiment and the achievement of temperature measurements.

2. Nuclear polarization. - The magnetic moment $\left(\mu_{n}\right)$ of nuclei of spin I is given by

$$
\mu_{\mathrm{n}}=\mathrm{g}_{\mathrm{I}} \mathrm{I} \beta_{\mathrm{n}}
$$

where $g_{I}$ is the gyromagnetic ratio of the nucleus and $\beta_{n}$ the nuclear Bohr magneton. In a magnetic field $(H)$ the thermal dependence of the nuclear polarization is a Brillouin function :

$$
f_{\mathrm{n}}=\mathscr{B}_{\mathrm{I}}\left(\frac{\mu_{\mathrm{n}} \mathrm{H}}{\mathrm{kT}}\right)
$$

Excluding the vicinity of the ordering temperature, where cooperative effects should occur and modify the magnetic field sensed by each nuclear spin, the nuclear polarization is a well known function of the temperature, and thermometers based on its measurement can be considered as primary. They require no calibration but only the knowledge of physical constants such as the nuclear magnetic moment $\mu_{n}$ and the applied magnetic field $H$. It should also be noted that these thermometers yield a spin temperature, which may be of importance in the case of decoupling between spin and lattice, which often occurs at very low temperature.

For a given temperature, the nuclear polarization depends on the quantity $\frac{\mu_{n} H}{k}$. As the order of magnitude for the moments of the different nuclei is the nuclear Bohr magneton, saturation effects occur only below $10^{-4} \mathrm{~K}$ for an applied field of $1000 \mathrm{Oe}$. Thus, in most practical cases, the nuclear polarization is weak and it is possible to use for the Brillouin function the following approximation

$$
B_{\mathrm{I}}(\mathrm{x})=\frac{\mathrm{I}+1}{3 \mathrm{I}} \mathrm{x}
$$

The problem then remains to measure the nuclear polarization with enough accuracy to yield the temperature with the required precision.

3. Measurement of nuclear polarization by coherent neutron scattering. - The scattering of thermal neutrons by nuclei of spin I is described in terms of the two spin state amplitudes $b_{+}$and $b_{-}$, which are associated with the total spin states $I+1 / 2$ and $I-1 / 2$ of the system formed by the neutron and the nucleus. For polarized nuclei, and in the absence of any electronic moment, the scattering amplitude is given by (2) :

$$
\hat{b}=\bar{b} \pm I B f_{n}
$$


with

$$
\begin{gathered}
\bar{b}=\frac{I+1}{2 I+1} b_{+}+\frac{I}{2 I+1} b_{-} \\
B=\frac{b_{+}-b_{-}}{2 I+1}
\end{gathered}
$$

where $f_{n}$ is the nuclear polarization, the sign \pm refers to the relative orientation of the neutron spin and the nuclear polarization. The coherent differential scattering cross section depends on the polarization $P_{n}$ of the beam :

$$
\sigma=\bar{b}^{2}+2 P_{n} \bar{b} I B f_{n}+\left(I B f_{n}\right)^{2}
$$

The quantity usually measured with the Bragg scattering of polarized neutrons is the flipping ratio $\mathrm{R}$ which is obtained for incoming neutrons polarized parallel $\left(\mathrm{P}_{\mathbf{n}}=+1\right)$ then antiparallel $\left(\mathrm{P}_{\mathrm{n}}=-1\right)$ to the nuclear polarization :

$$
R=\frac{\sigma^{+}}{\sigma^{-}}=\left(\frac{\bar{b}+I B f_{n}}{\bar{b}-I B f_{n}}\right)^{2}
$$

Solving equation (9) yields $\mathrm{IBF}_{\mathrm{n}}$, and then the nuclear polarization $f_{\mathrm{n}}$ without ambiguity. It requires only the knowledge of the quantity $B$ for the nucleus under consideration. For number of nuclei these quantities have already been tabulated $(3,4)$.

When $\operatorname{IBf}_{\mathbf{n}}$ is sma11 compared to $\overline{\mathrm{b}}$, which is generally the case, equation (9) may be written as

$$
R-1=4 \frac{\mathrm{IBf}_{\mathrm{n}}}{\overrightarrow{\mathrm{b}}}
$$

Considering approximation (4) for the Brillouin function one is led to

with

$$
\begin{aligned}
& R-1=\alpha \frac{H}{T} \\
& \alpha=\frac{4 B(I+1) g I B_{n}}{3 \bar{b} k}
\end{aligned}
$$

$\alpha \mathrm{H}$ represents the sensitivity of the thermometer, that is the magnitude of the polarized neutron signal $\mathrm{R}-1$ for a given temperature $T$. Table I reports the $\alpha$ values of some nuclei.

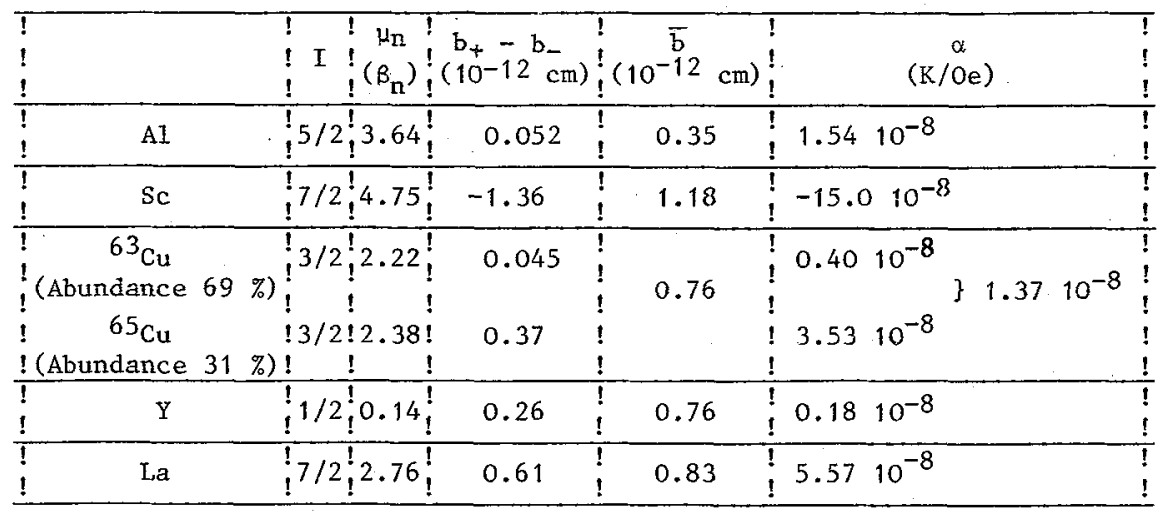

Table I - Sensitivity of some nuclei for measuring the temperature by nuclear polarization and the Bragg reflection flipping ratio.

We may note finally that though in principle measurement of the nuclear polarization by coherent scattering of polarized neutron may be performed on a polycrystalline target as well as on a single crystal, in practice, for counting rate 
reasons, single crystals are more suitable, particularly when the nuclear polarization is weak.

4. Spin dependent neutron capture. - The spin dependent neutron absorption by nuclei of spin I may be expressed by the 2 absorption cross sections $\sigma_{+}$and $\sigma_{-}$, which are also associated with the total spin states $J=I+1 / 2$ and $J=I-1 / 2$ of the neutron-nucleus system. According to Passel and Schermer (5), one can separate the absorption cross section into polarization-independent and polarization-dependent terms :

where

$$
\begin{aligned}
\sigma & =\sigma_{0}+P_{\mathbf{n}} f_{\mathbf{n}} \sigma_{\mathrm{p}} \\
\sigma_{0} & =\frac{I+1}{2 I+1} \sigma_{+} \frac{I}{2 I+1} \sigma_{-} \\
\sigma_{\mathrm{p}} & =\frac{\mathrm{I}}{2 I+1}\left(\sigma_{+}-\sigma_{-}\right)
\end{aligned}
$$

Transmission of neutron beams with polarization first parallel to the nuclear polarization $\left(P_{n}=+1\right)$ then antiparallel $\left(P_{n}=-1\right)$ enables a transmission flipping ratio to be defined

$$
R_{T}=\frac{T_{p}}{T_{A}}=\frac{e^{-N t\left|\sigma_{0}+f_{n} \sigma_{p}\right|}}{e^{-N t\left|\sigma_{0}-f_{n} \sigma_{p}\right|}}=e^{-2 N t f_{n} \sigma_{p}}
$$

where $\mathrm{N}$ is the number of nuclei per volume unit and $t$ the thickness of the sample.

The transmission of neutrons through the unpolarized sample permits the determination of the thickness as

$$
T=e^{-N t \sigma o}
$$

and then, from the transmission flipping ratio, the nuclear polarization $f_{n}$ and subsequently the temperature of the sample can be determined.

Here also, no temperature calibration is necessary, the measurement requiring only the knowledge of the nuclear quantities $\sigma_{0}$ and $\sigma_{p}$ (or, which is equivalent, $\sigma_{+}$ and $\left.\sigma_{-}\right)$.

In the case of ${ }^{3} \mathrm{He}(I=1 / 2)$, Passel and Schermer (5) have shown that the thermal $3 \mathrm{He}(n, p) T$ cross section is essentially all associated with a $J=0$ state of the compound system, which means that $\sigma_{p}=-\sigma_{0}$. The transmission flipping ratio is then

$$
\mathrm{R}_{\mathrm{T}}=\mathrm{e}^{2 \mathrm{~N} t \mathrm{f}_{\mathrm{n}^{\sigma}}}
$$

which is very convenient for nuclear polarization determination.

\section{Experiment (6)}

The experiment was set up on the polarized neutron diffractometer DN2 at the Melusine reactor of the C.E.N. Grenoble. The ${ }^{3}$ He target is made (figure 1) with $700 \AA$ powdered silver, sintered on two copper plates, of thicknesses 1.0 and $0.3 \mathrm{~mm}$ respectively. The target is squeezed between two aluminium plates. The polarizing field $(\mathrm{H}=800 \mathrm{Oe})$ is produced by SmCo5 permanent magnets. Very low temperatures are obtained by a dilution refrigerator in conjunction with a copper nuclear demagnetization stage, made of 20 moles of commercial copper wires. The initial and final demagnetization conditions lead to an estimated lowest temperature $\mathrm{T}_{\mathrm{Cu}}=0.3 \mathrm{mK}$ on the copper nuclei. To check the feasibility of cooling down the ${ }^{3}$ He target below its magnetic ordering temperature, two main temperature measurements had to be performed. The first one should check whether the sample container (C) reaches the temperature of the copper nuclear demagnetization stage (DS), and the second should verify that ${ }^{3} \mathrm{He}$ is below its Néel point. In an initial measurement, a copper single crystal was mounted on the sample container, as shown in figure 1. After the end of the nuclear demagnetization process, the neutron beam may be opened and reflection (111) of the monocrystal measured at regular time intervals. 

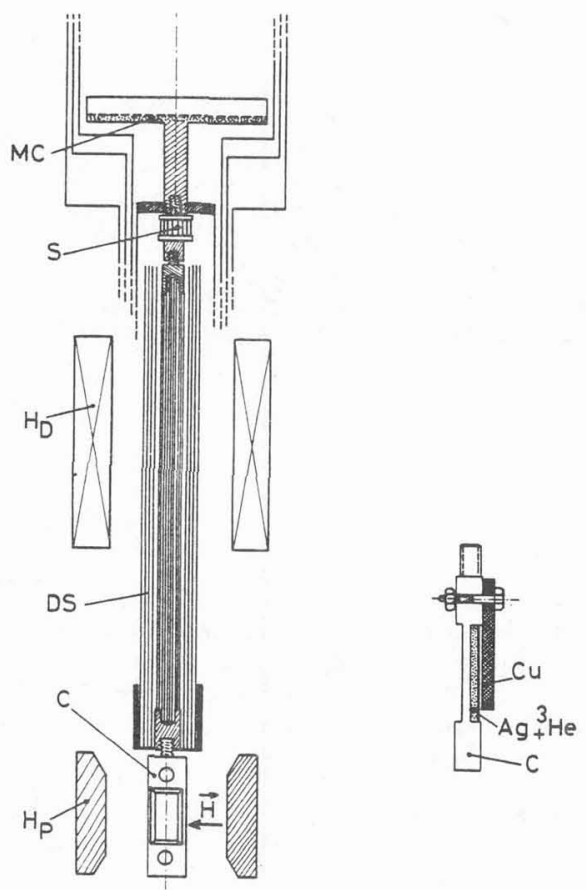

Figure 1 - The experimental set up : MC, S, $\overline{D S}, \mathrm{H}_{\mathrm{D}}, \mathrm{C}$ and $\mathrm{H}_{\mathrm{p}}$ are respectively the mixing chamber, the superconducting swith, the demagnetization stage, the demagnetization field, the container and the polarizing bield. Details of the experimental target are represented in the insert. A boat-like copper container $(\mathrm{C})$ is filled with silver sintered powder (Ag) and with ${ }^{3} \mathrm{He}$. A single crystal of copper ( $\mathrm{Cu}$ ) gives the temperature of $\mathrm{C}$ which is in a good thermal contact with DS by an electronic connection.

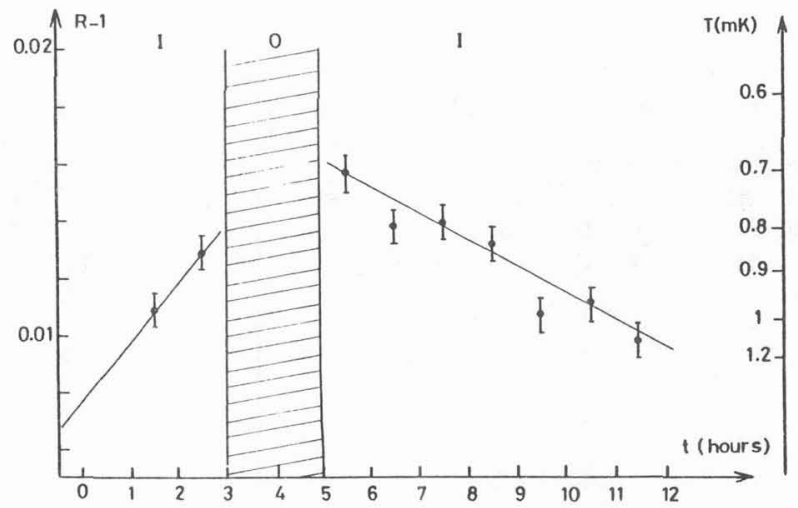

Figure 2 - Time variation of the container temperature as measured by the variation of the flipping ratio $\mathrm{R}$ of the 111 Bragg reflection of $\mathrm{Cu}$. The time origin corresponds to the end of the demagnetization. The beam is first open (I). closed (o) and open again (I).

Figure 2 shows a typical measurement of the temperature of the copper in which the beam had been opened for 3 hours, after the end of the demagnetization, and then closed for 2 hours before being reopened again. In this experiment a minimum temperature of $0.710^{-3} \mathrm{~K}$ has been reached.

To check whether the solid ${ }^{3}$ He temperature has reached the Néel point, it is no longer possible to use the Brillouin approximation (4) as exchange interactions play an important role in this temperature range. The simplest method is to compare the nuclear polarization with the susceptibility measurements (7).

Figure 3 shows the transmission flipping ratio as a function of the neutron irradiation time. In this experiment the neutron irradiation started 12 hours after the end of the nuclear demagnetization. The initial increase in the flipping ratio, and thus in the susceptibility shows clearly that experiments below $\mathrm{T}_{N}$ can be main- 


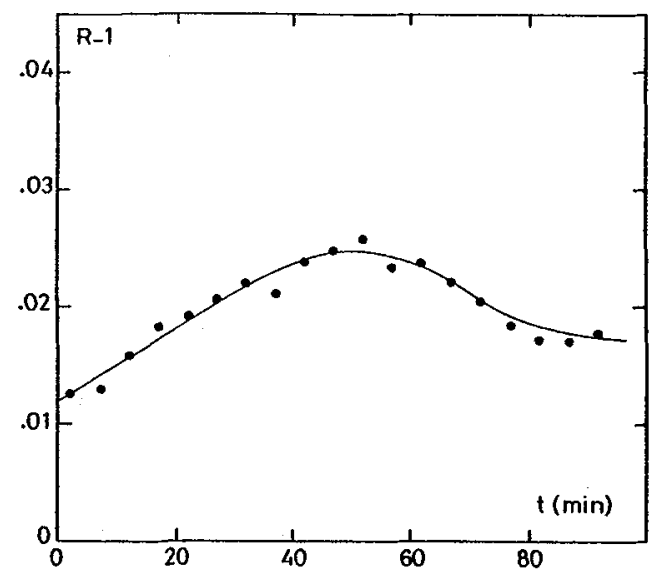

Eiaure 3 - Time dependence of the ${ }^{3}$ He transmission flipping ratio measured for a 3 He molar volume of $24.2 \mathrm{~cm}^{3}$ which corresponds to the melting curve $\left(\mathrm{T}_{\mathrm{N}} \sim 1 \mathrm{mK}\right)$. The time oricin correspands to the opening of the neutron beam.

tained during a time $t=50$ minutes after the opening of the neutron beam $\left(10^{4}\right.$ neutrons $/ \mathrm{sec})$. The factor 2 observed between the susceptibility measured at $t=0$ $\left(T<T_{N}\right)$ and the maximum susceptibility is in excellent agreement with thermodynamic measurements of Hata et al (7). This indicates that the temperature of the target is lower than $\mathrm{T}_{N}$ before the opening of the neutron beam.

The time variation of $f_{n}$, observed via the measurement of $R$ is related to the available magnetic entropy. The initial linear increase in $R$ can be understood by a slow conversion of the ordered phase to the paramagnetic phase at the ordering temperature. After $T_{N}$, the slow decrease in $R$, down to equilibrium, is due to the fact that solid $3_{\mathrm{He}}$ reaches it maximum $\mathrm{RLn} 2$ well above $\mathrm{T}_{\mathrm{N}}(8)$.

\section{References}

(1) LOUNASMAA 0.V., Experimental principles and methods below $1 \mathrm{~K}$, Academic Press Inc., London 1974.

(2) ITO Y., SHULl C.G., Phys. Rev. 185 (1969) 961.

(3.) GLATTLI H., BACCHELLA G.L., FOURMOND M., MALINOVSKI A., MERIEL P., PINOT M., ROUBEAU P., ABRAGAM A., J. Physique 40 (1979) 629.

(4) KOESTER L., RAUCH H., Summary of Neutron Scattering Lengths, IAEA Contract $2517 / R B$, July 1981 .

(5) PASSEL L., SCHERMER R.I., Phys. Rev. 150 (1966) 146.

(6) BENOIT A., FLOUQUET J., RUFIN D., SChWEIZER J., J. Physique-Lettres 43 (1982) 431.

(7) HATA T., YAMASAKI S., TANAKA Y., RODAMA T., SHIGI T., Physica 107B (1981) 201.

(8) HALPERIN W.P., RASMUSSEN F.B., ARCHIE C.N., RICHARDSON R.C., J. LOW Temp. Phys. 31 (1978) 617 . 